\title{
A Comparison of Montessori and Traditional School Children on Cognitive Development
}

\author{
Kavitha Sebastian $^{1 *}$, Dr Waheeda Matheen ${ }^{2}$
}

\section{ABSTRACT}

The present investigation was carried out to compare 4-6 year old Montessori and traditional school children on Cognitive Development with respect to logically related objects. The sample consisted of 4-6 year old boys and girls(sample size-72) drawn from four different schools. The tests were administered on a one-to-one basis. The task the children performed involved the recognition and recall of logically related objects i.e a seriation task. The test materials were drawn from the original work of Piaget with subsequent contribution from Yussen, Mathews and White(1980) who used these materials to determine the child's intellectual development in the acquisition of concrete operational thought. It was an ex post facto study. The statistics employed was the ' $t$ ' test. The results showed no significant differences between Montessori and traditional school children on Cognitive Development.

Keywords: Montessori, Traditional School, Children, Cognitive Development

We labour under a sort of superstition that the child has nothing to learn during the first five years of its life. On the contrary, the fact is that the child never learns in its after life what it does in its first five years (Gandhi, 1927).

Longitudinal research by Bloom (1964) has shown conclusively that half of all growth and intelligence present at 17 years takes place before the age of five, and the next 30 per cent is achieved between five and eight.

Certainly then, what happens to the young child is of critical importance in affecting his ability and motivation to learn. However, a child's capabilities vary tremendously from infancy to eight years of age with each stage having implications for the development of cognitive processes and educational programs (Valett, 1967).

\footnotetext{
${ }^{1}$ JBAS College for Women

2 JBAS College for Women

*Responding Author

(C) 2016 Sebastian K, Matheen W; licensee IJIP. This is an Open Access Research distributed under the terms of the Creative Commons Attribution License (http://creativecommons.org/licenses/by/2.0), which permits unrestricted use, distribution, and reproduction in any Medium, provided the original work is properly cited.
} 


\section{A Comparison of Montessori and Traditional School Children on Cognitive Development}

What should preschool and pre-primary children be taught? What are they capable of learning? These are two basic questions of age-old concern to educators which have again come under consideration due to recent research findings in developmental psychology (Valett, 1967).

Pedagogical practices evolve continually in order to take into account societal needs. During the 20th century, some educators and psychologists developed alternatives to the traditional approach (Besancon and Lubart, 2008).

Montessori (1958/2004) considered that imaginative thought must be based on contact with reality and sensory impressions. Based on these principles, she proposed targeted activities (such as learning how to see, feel, hear, and graduate colors or thermal stimuli...), beginning in preschool. The Montessori method, in existence for more than a century, is yet to enter mainstream pedagogy.

However, Montessori principles seem to be in accordance with what developmental psychologists have uncovered about how young children learn. Given the current educational climate, where enormous pressures are placed on educators to reverse achievement gaps in students by introducing more direct instruction and narrow training in academic skills in the early years. In many cases, changes in teaching strategies (such as removing time for purposeful play and exploration) are made even though they are not developmentally appropriate and not likely to produce lasting gains in literacy, math, and science (e.g., Neuman \& Roskos, 2005). It has been established that several factors other than academic performance play a vital role in future success. Therefore, a fresh look at teaching strategies and their effectiveness in imparting life skills is pertinent.

Moreover, young children today are under increasing pressure to perform academically resulting in stress for both the parent and child, when the child is unable to cope up. The Montessori method cleverly sidesteps the issue by adapting a curriculum that is dictated by the developmental level of the child. In this day and age of information explosion and media overexposure, the quiet confidence and patient reflection instilled by Montessori education is a welcome change that is beginning to be accepted by many. Because Montessori's contributions are often underappreciated by educators and psychologists, a fresh and close examination of them is certainly called for. A number of educational experts and researchers have noted that there is a paucity of research on Montessori education (Lillard, 2005). Therefore the implications of the Montessori method of education in relation to traditional schooling, on various aspects of child development including cognitive development is necessary to promote a better understanding of early childhood education. 


\section{A Comparison of Montessori and Traditional School Children on Cognitive Development}

\section{Research Problem}

Does the Montessori method of education by virtue of its emphasis on practical training and use of didactic materials enable a better conceptual understanding of underlying principles of subject material in young children?

\section{Operational Definition Of Variables}

Montessori Method : $\quad$ The method of education originated by Dr.Maria Montessori characterized by child-centered education, multi - age classrooms, use of didactic materials and self-directed learning on the part of the student.

Memory Task (Recognition : Memory Task, in context of this study refers to the of logically related objects)

\section{Traditional School} ability of the child to recognize logically related objects (pictures containing objects arranged in a seriesascending or descending) rather than the capacity for memory. This variable measures the child's ability to recognize a previously presented seriated array when later presented with a choice of the seriated array along with jumbled arrays.

Traditional schools are characterized by (1) central role assigned to the teacher: teacher is in front of the class; (2) an impersonal relation with pupils because there are many pupils in the class; and (3) the importance of abstract knowledge which is not always linked with everyday life (Danvers, 2003).

\section{Hypothesis}

1. There will be a significant difference between the performance of 4 - 6 year old Montessori and traditional school children on Memory Task (Recognition of logically related objects).

2. There will be no significant difference between the performance of $4-6$ year old boys and girls in Montessori and traditional schools on Memory Task (Recognition of logically related objects).

3. There will be no significant difference between the performance of $4-6$ year old first-born and later-born children in Montessori and traditional schools on Memory Task (Recognition of logically related objects).

\section{Research Design}

The present study was an ex post facto research conducted to compare students from Montessori and traditional schools on their performance in Memory Task (Recognition of logically related objects) targeting the acquisition of the piagetian concept of seriation. 


\section{A Comparison of Montessori and Traditional School Children on Cognitive Development}

\section{Variables of the Study}

The variables of the study are Method of schooling, gender, birth-order and Memory Task (Recognition of logically related objects).

\section{Nature of the Sample}

The sample consisted of 72 children in the age group of 4-6 years in Montessori and traditional schools in Chennai. 35 children were from Montessori schools with 20 males and 15 females in the age group of 4-6 years. 37 children were from traditional schools, 20 of whom are females and 17 males in the age group of 4-6 years. The children were randomly selected from two Montessori schools and two traditional schools.

Table 1: Sample Composition

\begin{tabular}{|c|c|c|c|}
\hline \multicolumn{4}{|c|}{ Total Sample : 72} \\
\hline \multicolumn{2}{|c|}{ Montessori school children } & \multicolumn{2}{|c|}{ Traditional school children } \\
\hline \multicolumn{2}{|c|}{35} & \multicolumn{2}{|c|}{37} \\
\hline Boys & Girls & Boys & Girls \\
\hline 20 & 15 & 17 & 20 \\
\hline
\end{tabular}

\section{Administration}

After obtaining school and parental consent; student profile sheet prepared by the researcher was sent to the parents who filled in the required information including date of birth, sex etc., of the child. The filled-in student profile sheets were collected and 20 children were randomly selected from each school trying to keep the number of boys and girls and 4-5 year olds and 5-6 year olds approximately equal.

The tests were administered individually on a one-to-one basis with a few minutes spent with each child to put the child at ease before the exercise was started.

\section{Tools for the Study}

1. A student profile sheet was used to collect personal information about the students. The researcher prepared this student profile sheet after reviewing numerous case study profile sheets used for research purposes.

2. Memory Task (Recognition of logically related objects) was drawn from the work of Yussen, Mathews and Knight (1980).

\section{Description Of The Tools}

1. The student profile sheet was designed by the researcher for collecting information about the subjects like date of birth, sex, birth-order etc.,

2. Memory Task (Recognition of logically related objects) draws upon the work of Yussen, Mathews and White (1980) who in their study on Montessori and traditional school children's 


\section{A Comparison of Montessori and Traditional School Children on Cognitive Development}

performance in social cognition and memory problems used the following task to determine the child's intellectual development in the acquisition of concrete operational thought. The child was given 10 study-test trials in which a single drawing was shown for 2-3 seconds, hidden, and a test array presented for recognition. In each test array, three of the drawings were highly similar to the original item, while one was identical to it. The child's task was to point to the picture that was "exactly the same" as the one just seen a moment ago. Each of the study-test trials consisted of different items. Eight of the study drawings depicted a series of six objects of different sizes (see Fig.1). Four were seriated in order as in the Fig.1, Example 1, while four appeared in reversed seriated order (see Fig.1, Example 2). The remaining two drawings depicted an object with a vertical orientation.' There was a ball suspended vertically from the boom of a crane and a flag situated vertically on a hill. For the eight seriation trials, the three distracter items on each test card consisted of two non-seriated arrays and a seriated array the reverse of the correct (target) one. For the two verticality items, the three distracter items all consisted of non-vertical arrangements of the key objects.

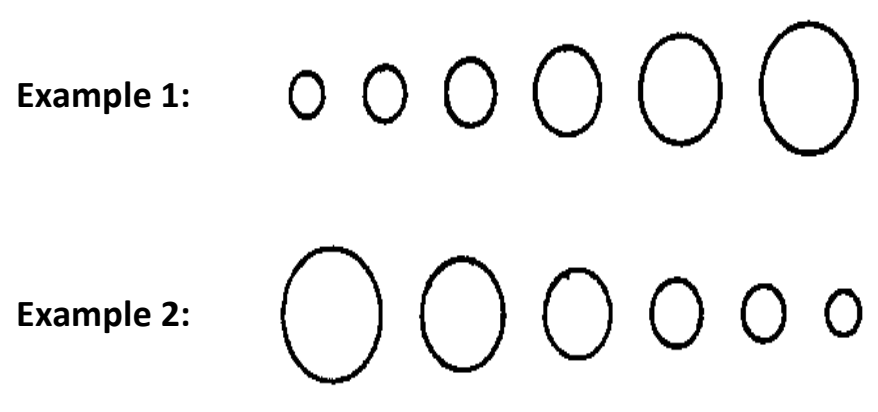

\section{Scoring}

A score of one was given for each correct response. The subject was given a score of one if he/she has correctly recognized that the drawings were presented in a series, even if the order (ascending or descending) was not correctly identified. For e.g. for the first item, both choices ' $c$ ' and ' $d$ ' are given a score of one, even though only ' $c$ ' is exactly the same as the test array

\section{Interpretation}

Higher the score, the higher was the subject's understanding of the relationship between the objects presented in the array. Subjects who obtain a perfect score of 10 have no difficulty in recognizing at a glance the logical relation between the objects presented in the array. They were therefore, able to engage in concrete operational thought.

\section{Statistics}

1. The 't'-test was used to compare difference in scores between Montessori and traditional school students, between the two sexes and between first-born and later-born children.

2. Chi square test 
RESULTS AND DISCUSSION

Table 2a shows Mean, SD, and 't'-value for Memory Task(Recognition of logically related objects) between 4 - 6 year old Montessori and traditional school students

\begin{tabular}{|l|l|l|l|l|l|l|}
\hline Test & School & N & Mean & SD & t & Significance \\
\hline $\begin{array}{l}\text { Memory } \\
\text { Task }\end{array}$ & Montessori & 35 & 7.3 & 3.09 & \multirow{2}{*}{ NS } \\
\cline { 2 - 5 } & Traditional & 37 & 6.73 & 2.66 & .86 & \\
\hline
\end{tabular}

NS - Not significant

Table 2a shows the Mean, S.D, and ' $t$ '-value for $4-6$ year old Montessori and traditional school children on performance in Memory Task (Recognition of logically related objects).

As seen from table 2a, there was no significant difference in the performance of $4-6$ year old Montessori and traditional school children in Memory Task (Recognition of logically related objects). Therefore, Hypothesis 1 which states that that there will be no significant difference in the performance of $4-6$ year old Montessori and traditional school children in Memory Task (Recognition of logically related objects) has been accepted.

The results of this study do not support the findings of Yussen, Mathews and Knight (1980), who in their study compared the performance of 4-year old children drawn from Montessori classroom with that of children attending traditional pre-schools. Among other findings, they reported that Montessori children excelled in Memory Tasks (Recognition of logically related objects).

Another study conducted on similar lines on the performance of Montessori and traditionally schooled nursery children on tasks of seriation, classification and conservation by White, Yussen and Docherty (1976) reported that significantly more Montessori than traditional children seriated and classified objects like concrete thinkers, but that there were no differences on the conservation problem.

From the results of the present study, it appears that Montessori children do not perform better than traditional school children in the Memory Task (Recognition of logically related objects) - a Piagetian task that targets the acquisition of the concept of seriation.

Though there is difference in performance between Montessori and traditional school children in the present study no statistically significant differences emerged on the ' $t$ '- test. One possible explanation could be the small size of the sample drawn from two Montessori and two traditional schools. The observed differences might have had a bigger effect in a larger sample.

A distinction was made between the number of children obtaining a perfect score (remembering and identifying all 10 test questions (pictures) correctly) and those obtaining imperfect scores. It 


\section{A Comparison of Montessori and Traditional School Children on Cognitive Development}

was speculated that children who obtained perfect scores of 10/10 had no difficulty in understanding the concept of seriation. The test is constructed in such a way that the children who could understand the concept of seriation will find it easy to answer all ten questions correctly (Refer appendix C).

A 2 X 2 Chi-square test was done to find out if significantly more number of Montessori children are perfect scorers in Memory Task (Recognition of logically related objects) than traditional school children.

Table $2 b$ shows the number of perfect and imperfect scorers for the Memory Task (Recognition of logically related objects) between 4 - 6 year old Montessori and traditional school children.

\begin{tabular}{|l|l|l|}
\hline School Type & Perfect Scorers & Imperfect Scorers \\
\hline Montessori children & 16 & 19 \\
\hline Traditional children & 7 & 30 \\
\hline
\end{tabular}

$\mathrm{X}^{2}$ value $=4.77$ (With Yates' correction for continuity)

For a 2X2 Chi-square table with one degree of freedom, the critical Chi-square value is 3.84, necessary to reject the null hypothesis at the 0.05 level of significance. As seen in table $4.6 \mathrm{~b}$, the Chi-square value 4.77 (with Yates's correction for continuity) exceeds the critical Chi-square value and therefore we can conclude that there is a significant relationship between the number of perfect scorers and the type of school. It was therefore proved that significantly more number of Montessori students are perfect scorers in Memory Task (Recognition of logically related objects).

The association between perfect scoring and the type of school (Montessori) that has emerged from the Chi-square test was an indication that the results of the present study need to be taken with caution. It is possible that the methodological flaw of a small sample could have affected the result of this study.

Table 3 shows Mean, SD, and 't'-value for Memory Task( Recognition of logically related objects) between 4 - 6 year old girls and boys from Montessori and traditional schools.

\begin{tabular}{|l|l|l|l|l|l|l|}
\hline Test & Gender & $\mathbf{N}$ & Mean & SD & t & Significance \\
\hline $\begin{array}{l}\text { Memory } \\
\text { Task }\end{array}$ & Boys & 38 & 6.84 & 2.96 & \multirow{2}{*}{ NS } \\
\cline { 2 - 5 } & Girls & 34 & 7.20 & 2.80 & .53 & \\
\hline
\end{tabular}

NS - Not significant

Table 3 shows Mean, SD, and 't'-value for Memory Task( Recognition of logically related objects) between girls and boys from Montessori and traditional schools.

(C) The International Journal of Indian Psychology, ISSN 2348-5396 (e)| ISSN: 2349-3429 (p) | 38 


\section{A Comparison of Montessori and Traditional School Children on Cognitive Development}

As seen in the table above, there was no significant difference between $4-6$ year old boys and girls in performance in Memory Task (Recognition of logically related objects). Therefore Hypothesis 2 which states that there will be no significant difference between $4-6$ year old boys and girls in performance in Memory Task (Recognition of logically related objects) has been accepted.

The present study was not in agreement with the findings of Meehan and Willis (1986), who in their study found males perform better than females in Piagetian Spatial Tasks (horizontality and verticality tasks).

From the findings of the present study it appears that the gender of the child does not influence performance in Memory Task (Recognition of logically related objects), a task which targets the acquisition of the Piagetian concept of seriation.

Table 4 shows Mean, SD and ' $t$ '-value for Memory Task (Recognition of logically related objects) between 4 - 6 year old first born and later born children.

\begin{tabular}{|l|l|l|l|l|l|l|}
\hline Test & Birth-order & $\mathbf{N}$ & Mean & SD & t & Significance \\
\hline $\begin{array}{l}\text { Memory } \\
\text { Task }\end{array}$ & First born & 43 & 7.02 & 2.65 & \multirow{2}{*}{} & \multirow{2}{*}{ NS } \\
\cline { 2 - 5 } & Later born & 29 & 7.00 & 3.22 & & \\
\hline
\end{tabular}

Table 4 shows the Mean, SD, and ' $\mathrm{t}$ '-value between $4-6$ year old first born \& later born children in performance in Memory Task (Recognition of logically related objects).

As seen in the table above, there was no significant difference between $4-6$ year old first born \& later born children in performance in Memory Task (Recognition of logically related objects).

Therefore Hypothesis 3 which states that there will be no significant difference between $4-6$ year old first born \& later born children in performance in Memory Task (Recognition of logically related objects) has been accepted. It may be interpreted that the birth order of the child does not influence performance in Memory Task (Recognition of logically related objects), a task which targets the acquisition of the Piagetian concept of seriation.

\section{CONCLUSIONS}

The following conclusions were drawn from the results of the study:

1. There was no significant difference between the performance of $4-6$ year old Montessori and traditional school children on Memory Task (Recognition of logically related objects).

2. There was no significant difference between the performance of $4-6$ year old boys and girls in Montessori and traditional schools on Memory Task (Recognition of logically related objects).

(c) The International Journal of Indian Psychology, ISSN 2348-5396 (e)| ISSN: 2349-3429 (p) | 39 


\section{A Comparison of Montessori and Traditional School Children on Cognitive Development}

3. There was no significant difference between the performance of $4-6$ year old first-born and later-born children in Montessori and traditional schools on Memory Task (Recognition of logically related objects).

\section{Acknowledgments}

The author appreciates all those who participated in the study and helped to facilitate the research process.

\section{Conflict of Interests}

The author declared no conflict of interests.

\section{REFERENCES}

Besançon, M., \& Lubart, T. (2008). Differences in the development of creative competencies in children schooled in diverse learning environments. Learning and Individual Differences, 18 (4), 381-389.

Bloom, B.S. (1964). Stability and change in human characteristics. New York: John Wiley.

Gandhi, M.K.(1927).The story of my experiments with truth. First edition. Navjivan Trust, Ahmedabad, India.

Lillard, A.S. (2005), Montessori: The science behind the genius. Oxford University Press, Oxford, ISBN: 0-19-516868-2, 2005, (cloth), pages 224.

Meehan, A.M., \& Willis, O.F. (1986). Gender Differences in Expectancies for Success and Performance on Piagetian Spatial Tasks. Merrill-Palmer Quarterly, 32 (4), 427-41.

Montessori, M. (1958/2004). Scientific pedagogy: volume 2, elementary education. Genève: Desclée de Brouwer.

Valett, R.(1967). A developmental task approach to early childhood education. Journal of School Psychology, Vol. 5(2), 1-2..

White, J.M., Yussen, S.R., \& Docherty, E.M.(1976). Performance of Montessori and Traditionally Schooled Nursery Children on Tasks of Seriation, Classification, and Conservation. Contemporary Educational Psychology, 1, 356-368.

Yussen, S.R., Mathews, S., Knight, J.W.(1980). Performance of Montessori and Traditionally Schooled Nursery Children on Social Cognitive Tasks and Memory Problems. Contemporary Educational Psychology, 5, 124-137.

How to cite this article: Sebastian K, Matheen W (2016), A Comparison of Montessori and Traditional School Children on Cognitive Development, International Journal of Indian Psychology, Volume 4, Issue 1, No. 81, ISSN:2348-5396 (e), ISSN:2349-3429 (p), DIP:18.01.124/20160401, ISBN:978-1-365-59365-9 